\title{
Isolation of Two Furanoditerpenes and Two Triterpenes from the Stem Bark of Dalbergia lanceolaria L.f.
}

\author{
Sharmin Sultana1 ${ }^{*}$, Fakir Shahidullah Tareq², Khondaker Miraz Rahman', \\ Choudhury Mahmood Hasan ${ }^{4}$
}

${ }^{1}$ Department of Pharmacy, University of Asia Pacific, Dhaka, Bangladesh

${ }^{2}$ Department of Pharmacy, Manarat International University, Dhaka, Bangladesh

${ }^{3}$ School of Cancer \& Pharmaceutical Sciences, King's College London, London, UK

${ }^{4}$ Department of Pharmaceutical Chemistry, University of Dhaka, Dhaka, Bangladesh

Email: *sharmin.sultana@uap-bd.edu

How to cite this paper: Sultana, S., Tareq, F.S., Rahman, K.M. and Hasan, C.M. (2019) Isolation of Two Furanoditerpenes and Two Triterpenes from the Stem Bark of Dalbergia lanceolaria L.f. Pharmacology \& Pharmacy, 10, 519-527.

https://doi.org/10.4236/pp.2019.1012043

Received: October 2, 2019

Accepted: December 7, 2019

Published: December 10, 2019

Copyright $\odot 2019$ by author(s) and Scientific Research Publishing Inc. This work is licensed under the Creative Commons Attribution International License (CC BY 4.0).

http://creativecommons.org/licenses/by/4.0/

\begin{abstract}
Stem bark of Dalbergia lanceolaria was subjected to methanolic extraction and extensive phytochemical separation. The process yielded four known compounds namely Jateorin (1), Columbin (2), $\beta$-sitosterol (3), and Lupeol (4). The compounds were identified using nuclear magnetic resonance spectral data namely ${ }^{1} \mathrm{H}$ NMR, ${ }^{13} \mathrm{C}$ NMR, ${ }^{1} \mathrm{H}-{ }^{1} \mathrm{H}$ COSY, HMBC, and DEPT-135 and verified by comparing the data with previous literature. All four compounds are being reported for the first time from the species $D$. lanceolaria. Furthermore, two furanoditerpenes namely Jateorin and Columbin are reported for the first time from the genus Dalbergia. This may lead to potential identification of a new chemotaxonomic marker for this genus.
\end{abstract}

\section{Keywords}

Dalbergia lanceolaria, Fabaceae, Jateorin, Columbin, Furanoditerpene, ${ }^{1}$ HNMR

\section{Introduction}

Fabaceae is one of the largest plant families consisting of about 730 genera and 14,900 species identified to date [1]. The genus Dalbergia belongs to the Faboideae sub-family and consists of 274 species distributed across the globe [2] [3]. Most of the species from this genus are timber trees including Dalbergia lanceolaria, the plant investigated here. It is tall deciduous tree distributed in Bangladesh, Bhutan, India, Sri Lanka, Myanmar, Thailand, Cambodia, Vietnam and Pakistan [2]. Its root bark is used by local population for dyspepsia and the 
leaves are used for skin disorders such as leprosy [4]. Oil extracted from its seeds is used for rheumatic and skin disorders [5].

Multiple studies have evaluated the biological activities of $D$. lanceolaria extracts and provided proof of anti-inflammatory, analgesic, and anti-diarrheal activity [4] [5] [6]. Only one study is available which investigated chemical constituents from the root barks and identified a new glycoside-namely Lanceolarin [7]. A large number of compounds have been identified from various other species of Dalbergia genus. Flavonoids were the most common type of compounds isolated, and some terpenes have also been identified [2] [8]. However, no alkaloid has been reported to date. Among the terpenes, triterpenes and sesquiterpenes are common but diterpenes have not been reported.

\section{Materials and Methods}

\subsection{Plant Collection and Identification}

For this study, the stem bark of the plant was collected from Chittagong Hill Tracts, Chittagong Division of Bangladesh. Plant was positively identified at Bangladesh National Herbarium and a voucher specimen was deposited for future reference (DACB Accession No. 43435).

\subsection{Preparation of Plant Extract}

Collected stem bark $(3.5 \mathrm{~kg}$ ) of $D$. lanceolaria was shed dried for 7 days and then pulverized by a high-capacity grinder to produce fine powder. $1.3 \mathrm{~kg}$ of the fine powder was soaked in $5 \mathrm{~L}$ of Methanol for 14 days and at the end of the 14-days soaking period, the methanol was evaporated in a rotary evaporator (Rotavapr, Butch, Switzerland) to procure $62.5 \mathrm{gm}$ of crude extract. This crude extract was partitioned between methanol and dichloromethane. After partitioning and subsequent evaporation, $6.88 \mathrm{gm}$ of $\mathrm{CH}_{2} \mathrm{Cl}_{2}$-soluble fraction was obtained.

\subsection{Chromatographic Separation}

The $\mathrm{CH}_{2} \mathrm{Cl}_{2}$-soluble fraction was further fractionated using vacuum liquid chromatography (VLC) technique as described in literature [9]. For this purpose, VLC-grade Kieselgel $60 \mathrm{H}$ Silica was used as the stationary phase. $6.4 \mathrm{gm}$ of the fractionation was mixed with $35 \mathrm{gm}$ of the stationary phase and placed on top of the packed column. Initially petroleum ether was used as the mobile phase and the fractionation was performed by progressively increasing solvent polarity with the addition of $\mathrm{CH}_{2} \mathrm{Cl}_{2}$ (up to $100 \%$ ), followed by addition of ethyl acetate (up to $100 \%$ ), and finally methanol (up to $100 \%$ ). A total of 40 sub-fractions were collected from VLC separation of $\mathrm{CH}_{2} \mathrm{Cl}_{2}$-soluble fraction. The sub-fractions were grouped by their TLC profiles and then further separated using LH20 Sephadex column chromatography with the mobile phase system starting with petroleum ether-chloroform (1:4) to $100 \%$ chloroform and ending with $100 \%$ methanol. This process afforded four compounds (compounds 1-4) which were further purified by preparative TLC. 


\section{Results}

Compound 1 (Figure 1) was obtained as a yellowish amorphous powder. The molecular formula was determined to be $\mathrm{C}_{20} \mathrm{H}_{22} \mathrm{O}_{7}$ from NMR data. The ${ }^{1} \mathrm{H}$ NMR spectrum (Figure 2) of 1 showed peaks at peaks at $\delta_{\mathrm{H}} 6.65,7.70$, and 7.75 which is indicative of protons in a furan ring. This spectrum also showed peaks at $\delta_{\mathrm{H}} 3.93$ and 3.63 indicating $\mathrm{H}-2$ and $\mathrm{H}-3$ in an epoxide ring. Singlet peaks at $\delta_{\mathrm{H}} 1.11$ and 1.04 were deduced to be from the two methyl groups (Me-18 and Me-20) and peak at $\delta_{\mathrm{H}} 5.00$ was deduced to be from $\mathrm{H}-1$ near the ether bridge. The complete structure was elucidated by the combination of ${ }^{1} \mathrm{H} N M R,{ }^{13} \mathrm{C}$ NMR, DPT-135, ${ }^{1} \mathrm{H}-{ }^{1} \mathrm{H}$ COSY, HMBC data and was found to be in agreement with those reported for Jateorin [10] [11].

Compound 2 (Figure 3) was obtained as yellow crystalline solid. The molecular formula of this compound was determined to be $\mathrm{C}_{20} \mathrm{H}_{22} \mathrm{O}_{6}$ from the NMR data. Similar to 1 , the spectrum showed peaks at $\delta_{\mathrm{H}} 6.46,7.46$, and 7.50 indicating presence of a furan ring. Singlet peaks at $\delta_{\mathrm{H}} 1.28$ and 1.10 corresponds to methyl groups. Presence of an ether bridge was indicated by a doublet peak at $\delta_{\mathrm{H}}$ 5.18 corresponding to $\mathrm{H}-1$. The complete structure was elucidated by evaluating ${ }^{1} \mathrm{H}$ NMR (Figure 4) and ${ }^{13} \mathrm{C}$ NMR data. The data was in agreement with previous literature reporting Columbin [12].

Compound 3 (Figure 5) was obtained as colorless needle-shaped crystals. ${ }^{1} \mathrm{H}$ NMR spectrum (Figure 6) showed peaks at $\delta_{\mathrm{H}} 3.51(\mathrm{~m}, 1 \mathrm{H}), 5.34(\mathrm{t}, 1 \mathrm{H}), 0.92$ $(\mathrm{d}, 3 \mathrm{H}, \mathrm{J}=6.48), 0.81$ (d, 3H, J = 6.12), 0.785 (d, 3H, J = 6.54), 0.67 (s, 3H), 0.998 $(\mathrm{s}, 3 \mathrm{H})$. The structure was elucidated from this data and was compared with previous literature reporting $\beta$-sitosterol [13]. Compound 4 (Figure 7) was white amorphous powder. ${ }^{1} \mathrm{H}$ NMR spectral data (Figure 8) from this compound gave peaks at $\delta_{\mathrm{H}} 3.18(\mathrm{dd}, 1 \mathrm{H}), 2.36(\mathrm{~m}, 1 \mathrm{H}), 1.91(\mathrm{~m}, 1 \mathrm{H}), 0.94(\mathrm{~s}, 3 \mathrm{H}), 0.75(\mathrm{~s}, 3 \mathrm{H})$, $0.82(\mathrm{~s}, 3 \mathrm{H}), 1.02(\mathrm{~s}, 3 \mathrm{H}), 0.91(\mathrm{~s}, 3 \mathrm{H}), 0.77(\mathrm{~s}, 3 \mathrm{H}), 4.56(\mathrm{~m}, 1 \mathrm{H}), 4.68(\mathrm{~m}, 1 \mathrm{H})$, and $1.67(\mathrm{~s}, 3 \mathrm{H})$. This data was in agreement with those reported for Lupeol [14].

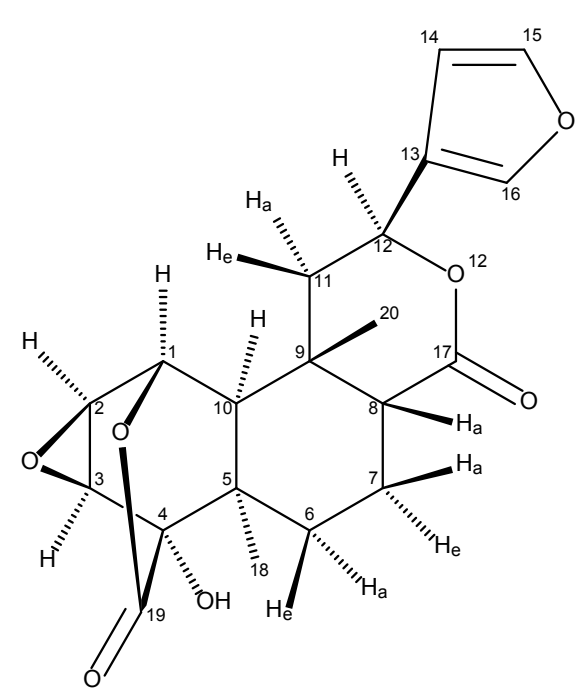

Figure 1. Elucidated structure of Compound 1. 


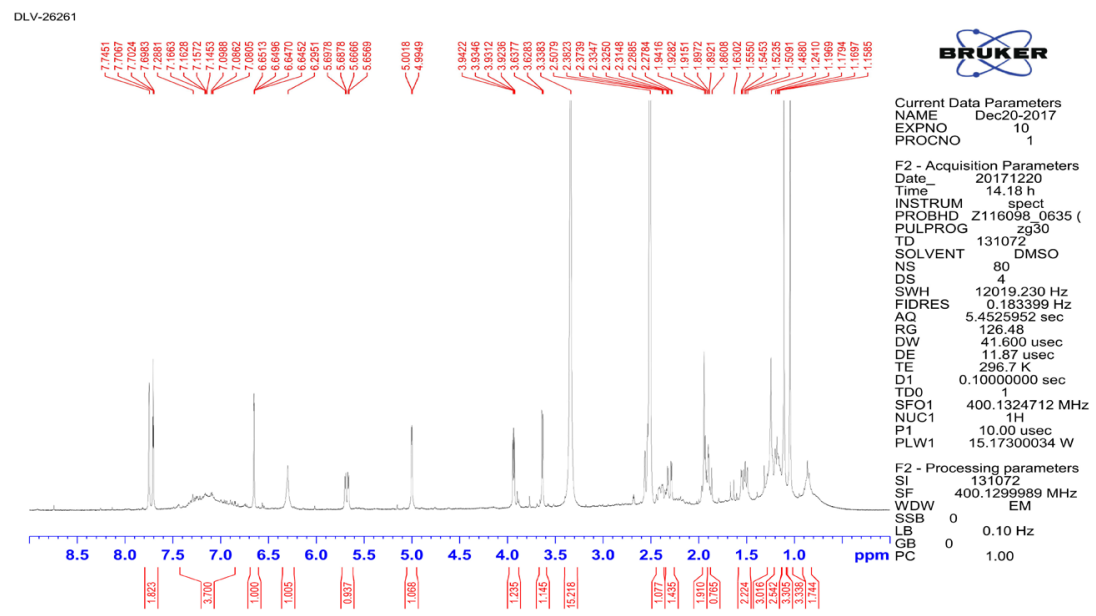

Figure 2. ${ }^{1} \mathrm{H}$ NMR spectrum of Compound 1. The spectrum was taken in Bruker $400 \mathrm{MHz}$ NMR instrument using dimethyl sulfoxide (DMSO) as the solvent.

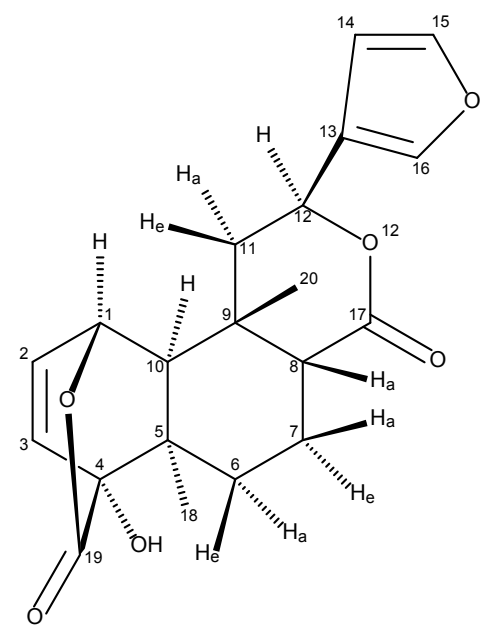

Figure 3. Elucidated structure of Compound 2.

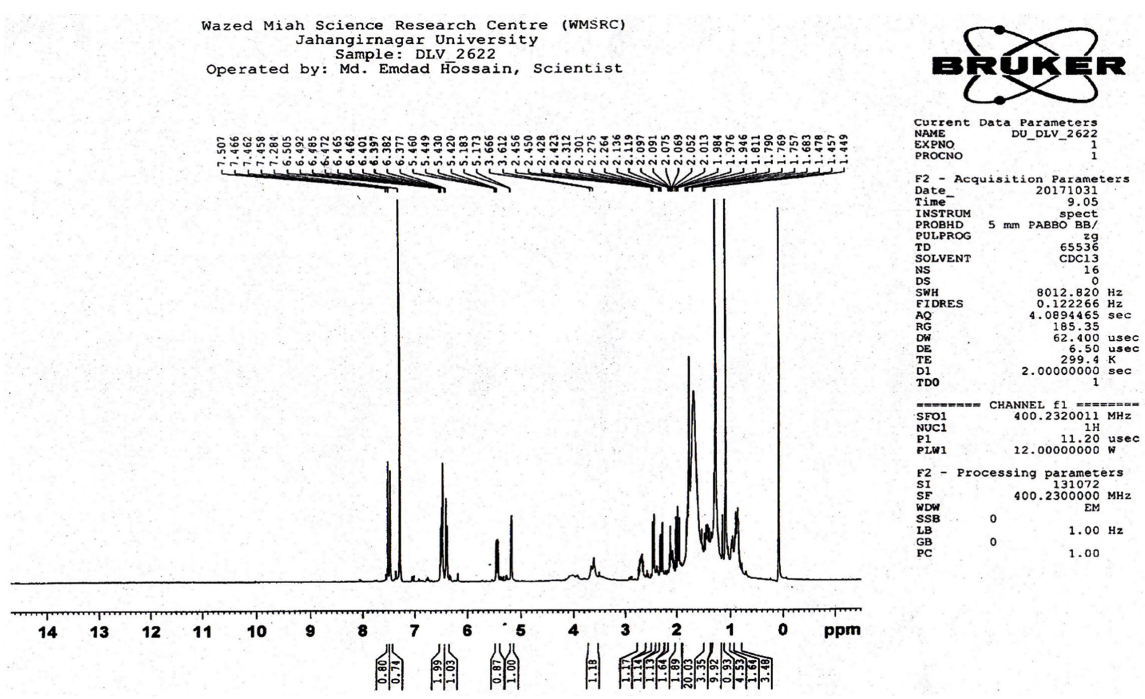

Figure 4. H NMR spectrum of Compound 2. The spectrum was taken in a Bruker 400 $\mathrm{MHz}$ NMR instrument using deuterated chloroform $\left(\mathrm{CDCl}_{3}\right)$ as the solvent. 


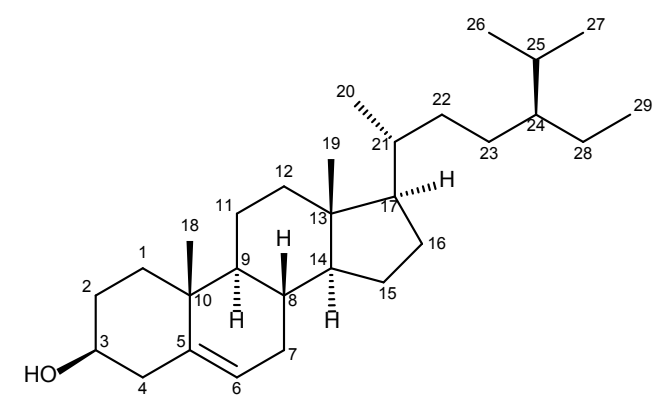

Figure 5. Elucidated structure of Compound 3.

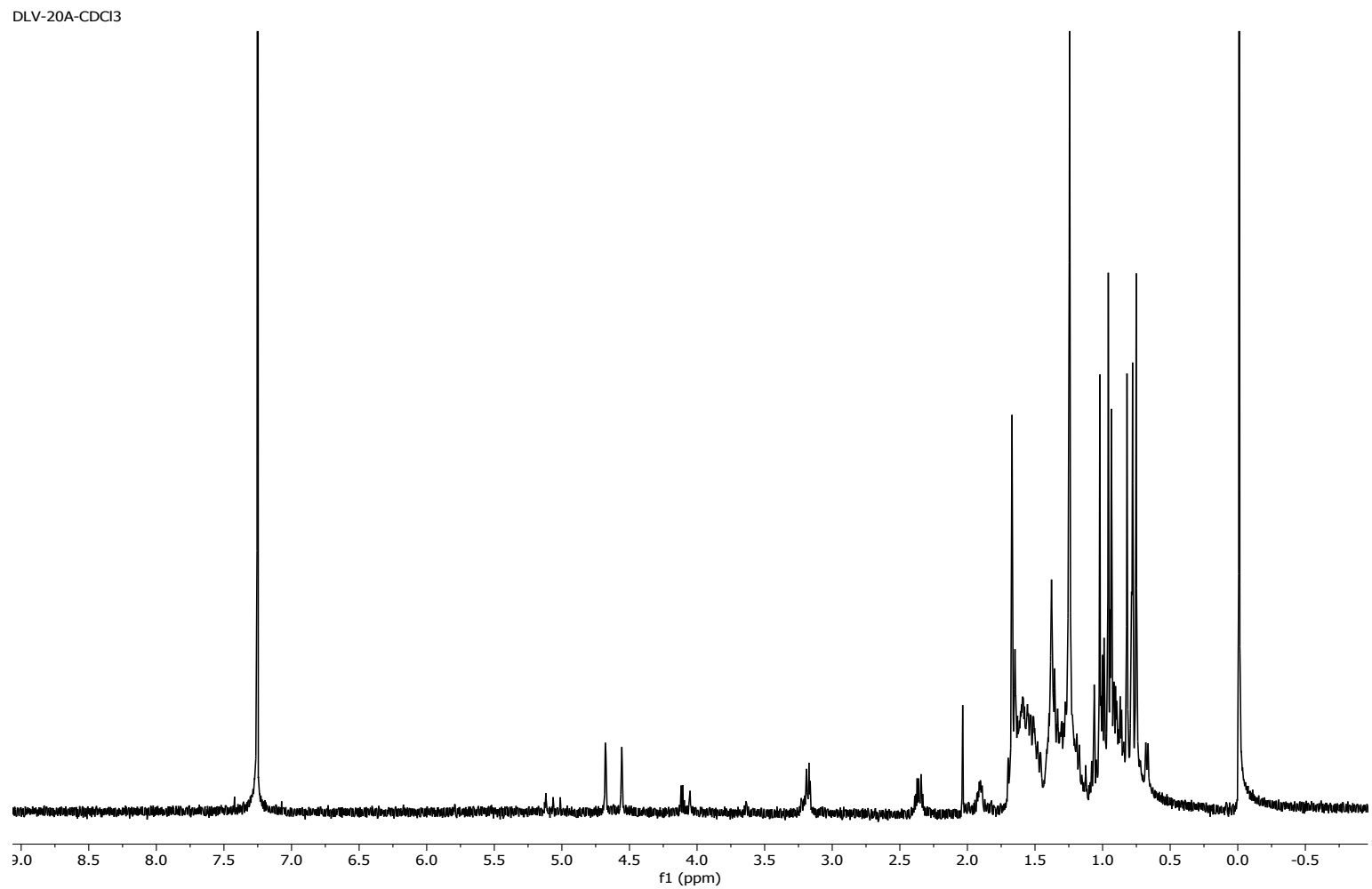

Figure 6. H NMR spectrum of Compound 3. This spectrum was taken from a Bruker $400 \mathrm{MHz}$ NMR instrument using deuterated chloroform $\left(\mathrm{CDCl}_{3}\right)$ as the solvent.

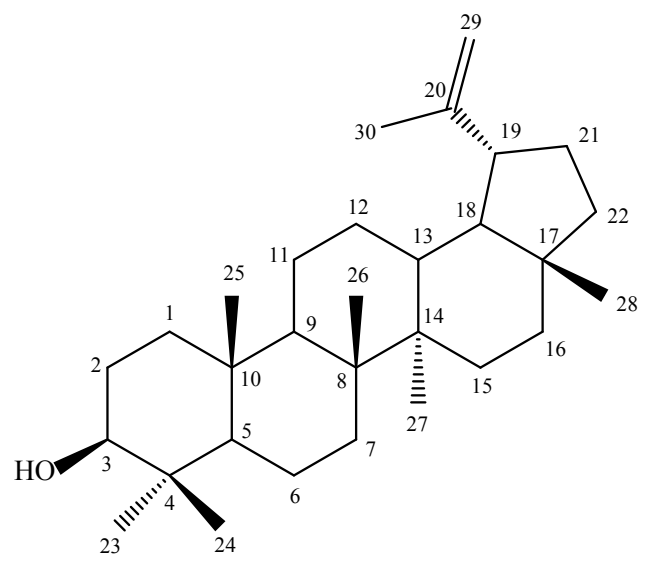

Figure 7. Elucidated structure of Compound 4. 


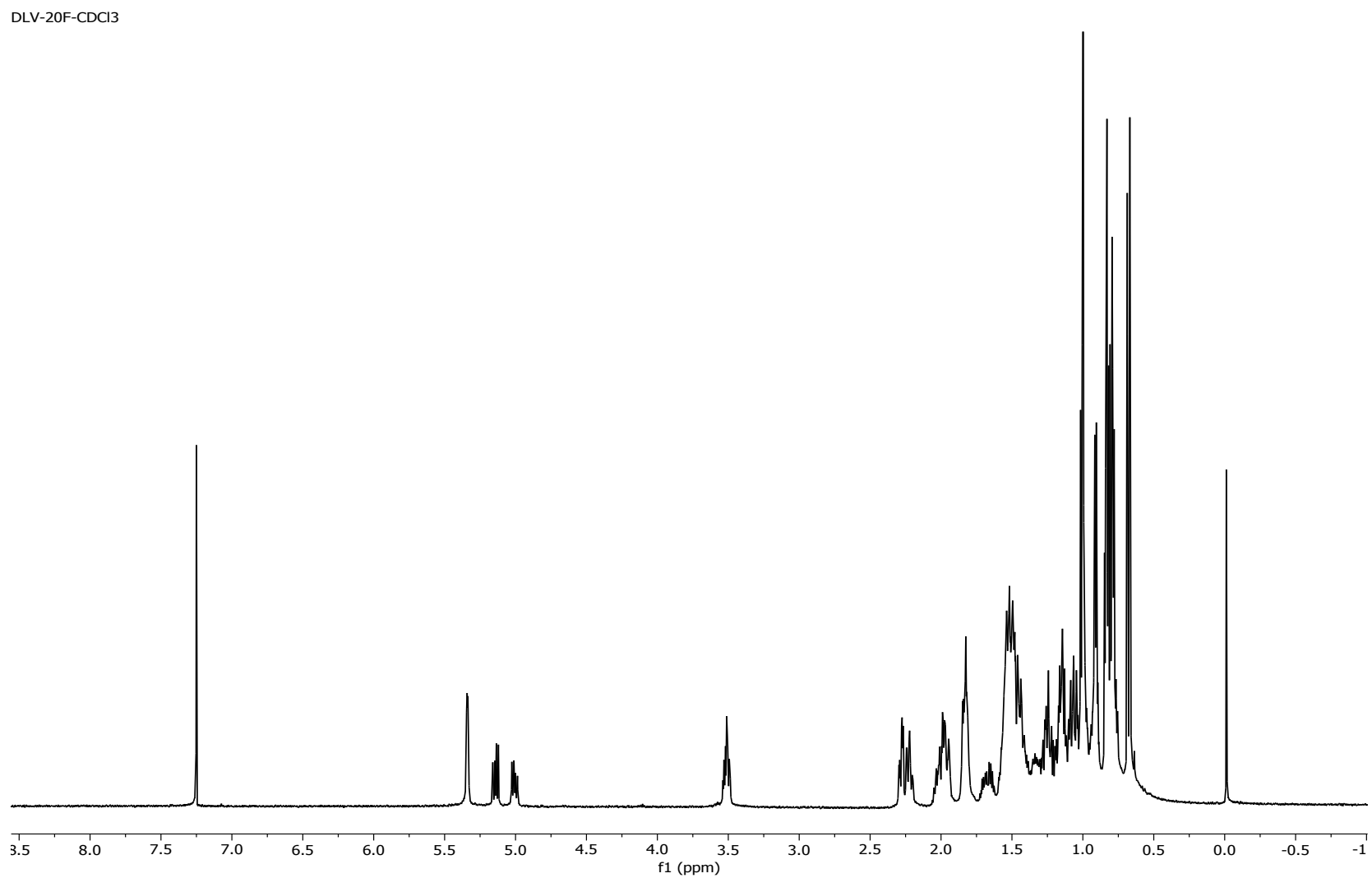

Figure 8. H NMR spectrum of Compound 4. This spectrum was taken using a Bruker $400 \mathrm{MHz}$ NMR instrument using deuterated chloroform $\left(\mathrm{CDCl}_{3}\right)$ as the solvent.

\section{Discussion}

Both $\beta$-sitosterol and Lupeol have been previously reported from $D$. hainanensis, D. latifolia, D. ecastophyllum, and D. miscolubium [8] [15] [16] [17]. In addition, $\beta$-sitosterol has been isolated from other species of Dalbergia genus such as D. rubiginosa, D. volubilis, D. sissoides, and D. sissoo [18] [19] [20] [21].

Furanoditerpenes are found in various plants within the Fabaceae family [22] [23] [24] [25]. However, diterpenes have not been reported for Dalbergia genus except for some Gibberelins identified in D. dolichopetala [26]. Compound 1 (Jateorin) and Compound 2 (Columbin) are furanoditerpenes which is a novel finding for this genus. To the best of the authors' knowledge, furanoditerpenes have never been reported in any publication for this genus. So, this finding is very interesting with respect to the phytochemistry of this species and the genus as a whole. Furthermore, all four compounds are being reported for the first time for D. lanceolaria.

\section{Conclusion}

In this present study, four compounds namely Jateorin, Columbin, $\beta$-sitosterol, and Lupeol were isolated from the methanolic extract of stem bark of $D$. lanceolaria. Among them, $\beta$-sitosterol and Lupeol are triterpenes and have been reported from other species within this genus. However, Jateorin and Columbin 
have not been reported previously from this genus. Hence, it is the recommendation of the authors that a systematic search be initiated to evaluate the presence of furanoditerpenes in other species within the Dalbergia genus.

\section{Acknowledgements}

The authors acknowledge that this investigation was funded by National Science and Technology Fellowship, Ministry of Science and Technology, People's Republic of Bangladesh.

\section{Conflicts of Interest}

The authors declare no conflicts of interest.

\section{References}

[1] Molares, S. and Ladio, A. (2012) The Usefulness of Edible and Medicinal Fabaceae in Argentine and Chilean Patagonia: Environmental Availability and Other Sources of Supply. Evidence-Based Complementary and Alternative Medicine, 2012, Article ID: 901918. https://doi.org/10.1155/2012/901918

[2] Saha, S., Shilpi, J.A., Mondal, H., Hossain, F., Anisuzzman, M., Hasan, M.M. and Cordell, G.A. (2013) Ethnomedicinal, Phytochemical, and Pharmacological Profile of the Genus Dalbergia L. (Fabaceae). Phytopharmacology, 4, 291-346.

[3] Thorne, R.F. (1968) Synopsis of a Putatively Phylogenetic Classification of the Flowering Plants. Aliso: A Journal of Systematic and Evolutionary Botany, 6, 57-66. https://doi.org/10.5642/aliso.19680604.06

[4] Mujumdar, A.M., Misar, A.V. and Upadhye, A.S. (2005) Antidiarrhoeal Activity of Ethanol Extract of the Bark of Dalbergia lanceolaria. Journal of Ethnopharmacolo$g y$, 102, 213-216. https://doi.org/10.1016/j.jep.2005.06.014

[5] Kale, M., Misar, A.V., Dave, V., Joshi, M. and Mujumdar, A.M. (2007) Anti-Inflammatory Activity of Dalbergia lanceolaria Bark Ethanol Extract in Mice and Rats. Journal of Ethnopharmacology, 112, 300-304. https://doi.org/10.1016/j.jep.2007.03.024

[6] Misar, A.V., Kale, M., Joshi, M. and Mujumdar, A.M. (2005) Analgesic Activity of Dalbergia lanceolaria. Bark Extract in Swiss Albino Mice. Pharmaceutical Biology, 43, 723-725. https://doi.org/10.1080/13880200500387331

[7] Malhotra, A., Murti, V.V.S. and Seshadri, T.R. (1967) Lanceolarin, a New Isoflavone Glycoside of Dalbergia lanceolaria. Tetrahedron, 23, 405-409.

https://doi.org/10.1016/S0040-4020(01)83326-3

[8] Guedes, G.M., Albuquerque, R.S., Soares-Maciel, R.S., Freitas, M.A., Silva, V.A., Lima, E.O., Lima, M.A., Cunha, E.V. and Coutinho, H.D. (2014) Isolation of Phytosterols of Dalbergia ecastophyllum (L.) Taub. (Leguminosae) and Modulation of Antibiotic Resistance by a Possible Membrane Effect. Arabian Journal of Chemistry, 12, 1576-1580. https://doi.org/10.1016/j.arabjc.2014.10.014

[9] Targett, N.M., Kilcoyne, J.P. and Green, B. (1979) Vacuum Liquid Chromatography: An Alternative to Common Chromatographic Methods. The Journal of Organic Chemistry, 44, 4962-4964. https://doi.org/10.1021/jo00394a045

[10] Yonemitsu, M., Fukuda, N., Kimura, T. and Komori, T. (1987) Studies on the Constituents of Jateorhiza palmata Miers (Colombo Root), II. Separation and Structure of Six New Furanoid Diterpene Glucosides: Palmatoside B, C, D, E, F, and G. Lie- 
bigs Annalen der Chemie, 1987, 193-197. https://doi.org/10.1002/jlac.198719870307

[11] Yonemitsu, M., Fukuda, N., Kimura, T. and Komori, T. (1986) Studies on the Constituents of Jateorhiza palmata Miers (Colombo Root), I Separation and Structure of a New Furanoid Diterpene Glucoside (Palmatoside A). Liebigs Annalen der Chemie, 1986, 1327-1333. https://doi.org/10.1002/jlac.198619860802

[12] Choudhury, M.K., Haruna, A.K., Johnson, E.C. and Houghton, P.J. (1997) Structural Education of Columbin, a Diterpene Isolated from the Rhizomes of Artisfolochia Albida. Indian Journal of Pharmaceutical Sciences, 59, 34-37.

[13] Nyigo, V.A., Peter, X., Mabiki, F., Malebo, H.M., Mdegela, R.H. and Fouche, G. (2016) Isolation and Identification of Euphol and $\beta$-sitosterol from the Dichloromethane Extracts of Synadenium glaucescens. The Journal of Phytopharmacology, 5, 100-104.

[14] Na, M., Kim, B.Y., Osada, H. and Ahn, J.S. (2009) Inhibition of Protein Tyrosine Phosphatase 1B by Lupeol and Lupenone Isolated from Sorbus commixta. Journal of Enzyme Inhibition and Medicinal Chemistry, 24, 1056-1059. https://doi.org/10.1080/14756360802693312

[15] Dhingra, V.K., Mukerjee, S.K., Saroja, T. and Seshadri, T.R. (1971) Chemical Examination of the Bark and Sapwood of Dalbergia latifolia. Phytochemistry, 10, 2551. https://doi.org/10.1016/S0031-9422(00)89912-4

[16] Silva, E.L.E. (2013) Estudo Químico Biológico de Dalbergia miscolobium Benth (Fabaceae). Master's Thesis, Universidade Federal do Espírito Santo, Vitória.

[17] Zhang, P.-C., Wu, Y. and Yu, D.-Q. (2003) Chemical Constituents from the Leaves of Dalbergia hainanensis. China Journal of Chinese Materia Medica, 28, 527-530.

[18] Al-Snafi, A.E. (2017) Chemical Constituents and Pharmacological Effects of Dalbergia sissoo: A Review. IOSR Journal of Pharmacy, 7, 59-71.

https://doi.org/10.9790/3013-0702015971

[19] Charles, J.A. and Gandhidasan, R. (2006) A New Isoflavone from Dalbergia rubiginosa (Roxb). Indian Journal of Chemistry, 45B, 1282-1284. https://doi.org/10.1002/chin.200639219

[20] Chawla, H., Chibber, S.S. and Seshadri, T.R. (1974) Volubilin, a New Isoflavone-C-Glycoside from Dalbergia volubilis Flowers. Phytochemistry, 13, 2301-2304. https://doi.org/10.1016/0031-9422(74)85043-0

[21] Ravi, P., Narayanan, V. and Raman, P.V. (1990) Constituents of Dalbergia sissoides. Fitoterapia, 61, 191.

[22] Jiang, R.-W., Ma, S.-C., But, P.P.-H. and Mak, T.C. (2001) New Antiviral Cassane Furanoditerpenes from Caesalpinia minax. Journal of Natural Products, 64, 1266-1272. https://doi.org/10.1021/np010174+

[23] Kitagawa, I., Simanjuntak, P., Mahmud, T., Kobayashi, M., Fuji, S., Uji, T. and Shibuya, H. (1996) Indonesian Medicinal Plants. XIII. Chemical Structures of Caesaldekarins c, d, and e, Three Additional Cassane-Type Furanoditerpenes from the Roots of Caesalpinia Major (Fabaceae). Several Interesting Reaction Products of Caesaldekarin a Provided by N-bromosuccinimide Treatment. Chemical and Pharmaceutical Bulletin ( Tokyo), 44, 1157-1161.

https://doi.org/10.1248/cpb.44.1157

[24] Oliveira, L.A., Oliveira, G.A., Lemes, G.F., Romão, W., Vaz, B.G., Albuquerque, S., Gonçalez, C., Lião, L.M. and Bara, M.T.F. (2017) Isolation and Structural Characterization of Two New Furanoditerpenes from Pterodon emarginatus (Fabaceae). Journal of Brazilian Chemical Society, 28, 1911-1916. https://doi.org/10.21577/0103-5053.20170029 
[25] Wei, H., Liu, X.-Q., Zhu, J.-J., Gao, L.-L., Wang, Z.-M. and Yan, L.-H. (2016) A New Cassane Diterpenoid from the Seeds of Caesalpinia decapetala. Journal of Asian Natural Products Research, 18, 371-375. https://doi.org/10.1080/10286020.2015.1055255

[26] Moritz, T. and Monteiro, A.M. (1994) Analysis of Endogenous Gibberellins and Gibberellin Metabolites from Dalbergia dolichopetala by Gas Chromatography-Mass Spectrometry and High-Performance Liquid Chromatography-Mass Spectrometry. Planta, 193, 1-8. https://doi.org/10.1007/BF00191599 